\title{
O LIXO VAI FALAR, E NUMA BOA: NÃO EXISTÊNCIA E MULHERES NEGRAS
}

\section{THE TRASH WILL TALK, AND IN A GOOD: NON-EXISTENCE AND BLACK WOMEN}

\section{Igor Thiago Silva de Sousa ${ }^{1}$ http://lattes.cnpq.br/0847237267749615 https://orcid.org/0000-0002-6283-1307}

Recebido em: 18 de dezembro de 2019.

Aprovado em: 18 de março de 2020.

RESUMO: Este artigo busca contribuir com as recentes discussões acerca do racismo, cruzando-as aos debates relativos ao machismo, colonialismo, modernidade, antagonismo estrutural e terror racial e as possibilidades de construção de um outro mundo possível a partir da experiência de mulheres negras em suas vivências, estratégias e produção de conhecimento. Esse debate se mostra crucial na esfera acadêmica, e sobretudo, entre militantes do movimento negro e feminista, por deslocar o sujeito de conhecimento habitual e nos conduzir a outras potências e possibilidades tanto práticas, quanto teóricas e analíticas, as das mulheres negras, ou se preferirmos, das negras mulheres, em suas múltiplas experiências, lutas e desafios.

Palavras-chave: racismo, machismo, mulheres negras, corpos negros.

\begin{abstract}
This article seeks to contribute to the recent discussions about racism, crossing them to the debates concerning machismo, colonialism, modernity, structural antagonism and racial terror and the possibilities of building another possible world from the experience of black women in their experiences., strategies and knowledge production. This debate proves crucial in the academic sphere, and especially among activists of the black and feminist movement, for displacing the subject of habitual knowledge and leading us to other practical, theoretical and analytical powers and possibilities, those of black women, or if We prefer black women in their multiple experiences, struggles and challenges.
\end{abstract}

Keywords: racism, machismo, black women, black bodies.

Para Albert Memmi (2010), o racismo contemporâneo não se ocuparia unicamente de fenômenos de ordem biológica. Trata-se de um álibi, um pretexto para legitimar a dominação sobre gentes consideradas inferiores, utilizáveis, exploráveis e por isso mesmo, sendo necessário dominá-las, conforme situa o autor:

Sigo pensando que el racismo, o de manera más general, el mecanismo que lo sostiene y del cual es un caso particular, resume y simboliza todo lo que he escrito en esos campos. Desde esta perspectiva, lo contiene todo y podemos encontrar todo en él: la dominación y la sujeción; la agresión y el miedo, la injusticia y la defensa de los privilegios, el alegato del dominador y su autopersuasión, el mito y la imagen negativa del dominado, la destrucción finalmente, la

${ }^{1}$ Antropólogo. Doutorando em Sociologia pela Universidade Federal do Rio Grande do Sul. E-mail: igorthiago.sousa@, gmail.com 
anulación de la víctima en provecho de su verdugo. Con la condición de que, por supuesto, se perciba claramente esa generalidad de la forma de actuar racista. No se trata de un círculo, en el que pido que se me otorgue por adelantado lo que pretendo demostrar; es limitarse a las conductas comprobables de la mayoría (MEMMI, 2010, p. 02).

Para tal debate, Memmi realiza uma diferenciação entre dois tipos de racismo. Um seria restrito e outro lato. No primeiro, tem-se um racismo assentado em características biológicas, como tons de pele, formato do nariz, boca, altura; no segundo caso, baseia-se em características outras:

Existe, en efecto, un racista en el sentido estricto: ese que, remitiéndose a diferencias biológicas entre él y el otro, aprovecha para abrumar a ese otro y sacar provecho. Ese que cree poder juntar sus rasgos diferenciales en constelaciones coherentes, a las cuales denomina razas: la del otro, impura y aborrecible; la suya: pura y admirable. Ese que, a nombre de esa superioridad particular, pretende gozar de manera legítima de beneficios de otro tipo: económicos, por ejemplo, o políticos, o incluso psicológicos o simplesmente de prestigio (MEMMI, 2010, p. 02).

E continua o autor, apontando as características do sentido lato:

Pero también existe, indiscutiblemente, un racismo en el sentido amplio - esta palabra deja entonces de convenir - en el cual el acusador, ignorando o no las diferencias biológicas, se complace, sin embargo, con la misma actitud, en nombre de otras diferencias. Se trata siempre de valorizarse y de desvalorizar al otro, para desembocar en la misma conducta: una agresión, verbal o efectiva (MEMMI, 2010, p. 03).

Racismo lato refere-se a aspectos culturais, religiosos ou étnicos. Nesse sentido, ao invés de entender essas formas de racismo como estanques e congeladas, o autor avança ao pensar em formas comuns que situem estes tipos. Para o Memmi, o racista é uma figura que tem medo, aquele que agride e deseja aniquilar porque tem medo da agressão, tem medo da diferença, da contaminação, tem a obrigação de defender seus bens contra inimigos ameaçadores, sua propriedade, a civilização, a pureza racial. ¿Por qué ese miedo a ser agredido? Por lo general para arrebatar o defender algún bien (MEMMI, 2010).

Assim, o racismo se explica pela dominação, pela capacidade de extração, de subjugar e explorar um outro. Este vale-se de tons de pele, supostos atributos físicos, mentais ou características relativas à nacionalidade, religiosidade, origem étnica ou regional, a partir dos quais tem-se a possibilidade de assegurar esquemas de exploração. Para dar conta desse leque ampliado, o autor conceitua heterofobia.

Me parece que la palabra heterofóbico convendría bastante bien a esa categoría de personas. Heterofobia podría designar esas constelaciones fóbicas y agresivas, dirigidas contra el otro, que pretenden legitimarse con base en argumentos diversos, psicológicos, culturales, sociales o metafísicos, y entre las cuales el racismo, en el sentido biológico, sería una variante. Hasta donde sé, ese término no existe en el diccionario, pero, ahí también, espero que la necesidad y el uso lo impongan. Muchas personas se creen absueltas del pecado de racismo si no le prestan atención al color de la piel, la forma de la nariz o el espesor de los labios: ¿son menos condenables si agraden al otro por una fe o por costumbres diferentes? (MEMMI, 2010, p. 70). 
Nesse sentido, Memmi avança ao pensar em formas de racismo contemporâneas, ligadas a aspectos religiosos (islamofobia na Europa ou perseguição a cultos de matriz afro no Brasil, para citar alguns exemplos que podem ser depreendidos), relacionados a origem nacional (ódio contra africanos, árabes ou mesmo judeus) e de origem étnica (ciganos na França ou no restante da Europa Ocidental). Por sua vez, pensando em um diálogo profícuo entre autores, é possível vislumbrar semelhanças entre as elaborações de Albert Memmi (2010) e Achille Mbembe (2014). Para o último autor, raça se trata de alterocídio, uma construção fictícia, um complexo perverso em que o outro deve ser indissociavelmente combatido, deve ser destruído ou "administrado", se possível. É, sobretudo uma representação fictícia de outras gentes:

Quanto ao resto, trata-se do que se apazigua odiando, mantendo o terror, praticando o alterocídio, isto é, constituindo o Outro não como semelhante a si mesmo, mas como objecto intrinsecamente ameaçador, do qual é preciso proteger-se, desfazer-se, ou que, simplesmente, é preciso destruir, devido a não conseguir assegurar o seu controlo total (MBEMBE, 2014, p. 26).

Se é uma construção imagética e fictícia, esta não deixa de construir e atuar sobre a realidade. Como bem salienta Mbembe, ao pensar na África em especial e nos negros em específico, raça trata-se da capacidade de perceber o outro como desprovido de humanidade, logo, ausência de universalidade, enquanto ser animalizado, desprovido de razão, ou qualquer outra capacidade humana, sendo a ele reservada a condição daquele que se combate, aquele do qual se protege a família e propriedades. Assim, tanto a África, quanto o negro são lidos como ausências, incapacidades, aquele que se odeia, por isso se presume uma violência, logo, deve ser violentado gratuitamente.

Ao falar do complexo escravagista, do tráfico e do que dali se sucedeu em termos de um racismo antinegro, por assim dizer, Achille Mbembe é enfático ao dar seu destaque na relação entre racialização, sistema capitalista e suas consequências na expansão europeia.

Seria erróneo pensar que saímos definitivamente deste regime, do qual o comércio negreiro e, depois, a colónia de plantação ou simplesmente de exploração foram o panorama originário. Nestas fontes baptismais da nossa modernidade, pela primeira vez na história humana, o princípio de raça e o tema com o mesmo nome foram instaurados sob o signo do capital, e é precisamente este ponto que distingue o tráfico negreiro e as suas instituições das formas autóctones de servidão. Com efeito, entre os séculos XIV e XIX, o horizonte espacial da Europa alargouse consideravelmente. O Atlântico foi-se tornando o epicentro de uma nova concatenação de mundos, o lugar de onde emergiu uma nova consciência planetária. Este acontecimento dá seguimento às anteriores tentativas europeias de expansão em direcção às Canárias, Madeira, Açores e ilhas de Cabo Verde, resultado de um começo da economia de plantação com mão-de-obra de escravos africanos (MBEMBE, 2014, p. 31).

Atentando para a provocação nas elaborações sobre tráfico negreiro, escravidão negra, e as complexas tramas do que se convencionou chamar de diáspora africana, é importante repensar as associações comuns sobre a modernidade e sua relação com escravidão ou mesmo as próprias narrativas sobre as conquistas imperiais. Tem-se chamado a atenção para narrativas autocentradas que tendem a definir a Europa como autônoma em relação a outros continentes e gentes nesta elaboração (CHAKRABARTY, 2009). Como se a modernidade lhe fosse um feito próprio e autóctone, sem outras gentes. Outra crítica "refere-se as asserções universalistas 
do projeto iluminista, que, teoricamente, valiam para a humanidade como um todo mesmo que se pretendesse definir humanidade em termos bastante restritos" (GILROY, 2012, p. 105).

Assim, trazer à tona o processo de subordinação de povos não-europeus em geral e africanos e afros em especial, mostra-se indispensável, mesmo que comumente passe desapercebido, permitindo-se vislumbrar a fuga de visões inocentes e simplistas da modernidade, estas mais usuais e acessíveis. O que se almeja é evocar a modernidade em seu terror racial associandoa tanto ao surgimento do capitalismo quanto a sua indissociabilidade do colonialismo, em sua produção de esquemas de escalonamento, sobre supostos lugares de onde se deveria sair e linhas mestras que se deveria seguir, seja sob a nau de elites locais ou colonizadores, a chave seria avançar ao moderno. Belas capitais, pujança material e efervescência cultural são associadas diretamente a um lastro de saque e escravidão que liga cidades como Paris, Berlim e Londres à África e a instituição da escravidão racial no "Novo Mundo" e ao tráfico negreiro no continente africano.

A experiência da modernidade, a partir de outro prisma mostra-se vital para pensar como "as experiências históricas características das populações dessa diáspora [negra] criaram um corpo único de reflexões sobre a modernidade e seus dissabores, que é uma presença permanente nas lutas culturais e políticas de seus descendentes atuais” (GILROY, 2012, p. 108).

Achille Mbembe ao pensar no processo de transnacionalização da condição negra situa que esta é um momento constitutivo da modernidade:

A transnacionalização da condição negra é, portanto, um momento constitutivo da modernidade, sendo o Atlântico o seu lugar de incubação. Esta condição contém em si toda uma panóplia de situações muito contrastantes, que vão do escravo traficado, tornado objecto de venda, ao escravo condenado, ao escravo de subsistência (doméstico para toda a vida), ao escravo rural, ao de câmara, ao alforriado, ou ainda ao escravo liberto ou ao escravo de nascença (MBEMBE, 2014, p. 34).

Ao pensar em escravidão, vale situar experiências múltiplas de resistência e configuração da condição negra no "Novo Mundo", fugindo assim de estereótipos que tendem a ver o escravo ora como pura passividade, ora como um guerreiro nato. Me parece que esse é o esforço de Mbembe ao situar diferentes facetas da escravidão e consequentemente diferentes experiências, que se ligadas pelo selo da desumanização, não se configuram do mesmo jeito, em termos de acessos a bens e possibilidades de liberdade.

Assim, em suas reivindicações, raça também é a resposta dada pelo colonizado ao ódio do colonizador, o ressentimento produzido pela exploração, abjeção, pela impossibilidade de compartilhar atributos de humanidade em que:

Raça é também o nome que deve dar-se ao ressentimento amargo, ao irrepreensível desejo de vingança, isto é, à raiva daqueles que lutaram contra a sujeição e foram, não raramente, obrigados a sofrer um sem-fim de injúrias, todos os tipos de violações e de humilhações e inúmeras ofensas (MBEMBE, 2014, p. 26).

Assim, se raça é a ficção pela qual se condena outrem a não humanidade, é também a saída encontrada por aqueles desprovidos de universalidade, a resposta dada ao olhar branco, a criação de um outro inferior. Aqui pode-se avançar um pouco mais no diálogo, em que a figura do colonizado frente ao branco aparece atônita, insegura, ora com medo, ora com ódio, ora 
com desejo de vingança, conforme situa Frantz Fanon:

Depois tivemos de enfrentar o olhar branco. Um peso inusitado nos oprimiu. O mundo verdadeiro invadia o nosso pedaço. No mundo branco, o homem de cor encontra dificuldades na elaboração de seu esquema corporal. O conhecimento do corpo é unicamente uma atividade de negação. É um conhecimento em terceira pessoa. Em torno do corpo reina uma atmosfera densa de incertezas (FANON, 2008, p. 104).

Nesse sentido, o negro frente ao branco é aquele que é atravessado por insegurança, aquele que performa sua corporalidade e tem que lidar com um olhar que o reduz, situa, mapeia e oprime, lhe retira os atributos de dignidade. A tentativa de passar desapercebido se mostra em vão, descobre-se ser objeto em meio a outros, se exige mais do que o ofertado, mais um suplemento e a tentativa de encenação cai por terra após ataques. Reclui-se, encolhe-se, mas onde se esconder? Não se é ignorado. Há negridão por todo corpo que é impossível não ver.

O que é que isso significava para mim, senão um desalojamento, uma extirpação, uma hemorragia que coagulava sangue negro sobre todo o meu corpo? No entanto, eu não queria essa reconsideração, esta esquematização. Queria simplesmente ser um homem entre outros homens. Gostaria de ter chegado puro e jovem em um mundo nosso, ajudando a edificá-lo conjuntamente (FANON, 2008, p. 106).

Se exige explicações, se tem raiva e é com ela que se explode, e o corpo que eclode é reunido por um outro eu. Na ausência de reconhecimento se faz necessário fazer conhecer (FANON, 2008, 109). Evoca-se assim uma pluralidade negra que se não deve ser reduzida a raça, nem por isso deixa de estar atravessada por tal acontecimento e é na pluralidade que se faz, em manifestações múltiplas que recusam o sentimento de inexistência. Seguindo esse caminho, gostaria de explorar um tipo de análise centrada na díade negro e não-negro. Nesse tipo de abordagem, o pertencimento a humanidade, não se daria pela maior aproximação ao branco (com toda a constelação que a ele e seu mundo são dados), mas justamente pelo maior e progressivo afastamento do negro, uma migração no sentido de recusa, distanciamento e apagamento. Aqui, frisa-se um alargamento da concepção de humanidade, que inclui pessoas não-brancas e não-negras em que:

Nesse contínuo mais abrangente, graus de Humanidade não são conferidos a partir da branquitude, mas em relação à distância relativa da negritude. O conjunto da Humanidade, então, inclui pessoas brancas bem como pessoas não-brancas e não-negras. Ser humano é ser não-negro (VARGAS, 2017, p. 86).

Gozar de expectativa de vida digna, saúde, acessos a equipamentos públicos e alguma estabilidade econômica não estaria restrito a pessoas brancas, mas seria exclusivo de pessoas nãonegras em que, o elemento constituinte da humanidade seria o não ser negro, conforme situa Vargas:

Essa não-referência à não pessoa negra faz com que, não somente brancos, mas todas pessoas não-negras, derivem sua subjetividade e seus privilégios sociais relativos do fato de não serem negras. A pessoa negra, assim, não faz parte da Humanidade; essa pessoa torna possível, mas não é parte da hierarquia Humana (VARGAS, 2017, p. 87). 
Ao pensar nas possibilidades de experiências múltiplas frente a desumanização, construções de conhecimento, de partilha da vida, cuidado e da criação de estratégias frente a violência e morte gratuitas, nos chama a atenção a elaboração de Patricia Hill Collins (2016) sobre lugares ocupados por mulheres negras em um mundo que as desumaniza, as torna menores em um mundo já tornado pequeno, as coloca numa quarta posição: das exploradas dos explorados, das menores entre os já pequenos. Em seu esforço, a autora pensa em esquemas de construção de conhecimento entre mulheres negras, em como suas vivências, conhecimentos e a condição de partilha de experiências a partir do lugar de outsider within. Tal lugar pode-se definir pela estrangeirice, pelo deslocamento, pela invisibilidade, pelo não pertencimento ao lugar ocupado, pois ao mesmo tempo que se periga ocupar espaços hegemonicamente brancos e masculinos e se compartilha sensibilidades e/ou aptidões profissionais, tais atributos não asseguram a mesma condição, pois se tem o jugo do racismo antinegro. Estar lá não significa igualdade, conforto, mas não estar entre pares, sejam eles brancos ou brancas, pois mesmo dominando os códigos de acesso, mesmo se tendo alguma sensibilidade em jogo, não impedem que a epiderme compute como significante, que haja abjeção e desumanização incessante dos corpos negros.

Nesse sentido, a autora faz uma proposição sobre a possibilidade de construção de conhecimento entre mulheres negras a partir de diferentes experiências, da partilha de certos vínculos, códigos e do prisma do feminismo negro. Eis uma aposta instigante:

A insistência quanto à autodefinição das mulheres negras remodela o diálogo inteiro. Saímos de um diálogo que tenta determinar a precisão técnica de uma imagem para outro que ressalta a dinâmica do poder que fundamenta o próprio processo de definição em si. Feministas negras têm questionado não apenas o que tem sido dito sobre mulheres negras, mas também a credibilidade e as intenções daqueles que detêm o poder de definir. Quando mulheres negras definem a si próprias, claramente rejeitam a suposição irrefletida de que aqueles que estão em posições de se arrogarem a autoridade de descreverem e analisarem a realidade têm o direito de estarem nessas posições. Independentemente do conteúdo de fato das autodefinições de mulheres negras, o ato de insistir na autodefinição dessas mulheres valida o poder de mulheres negras enquanto sujeitos humanos (COLLINS, 2016, 103-104).

Assim, para Hill Collins seria possível compartilhar certas experiências em comum com mulheres negras empregadas domésticas nos EUA a partir de sua própria vivência racial enquanto outsider within; na condição de professora universitária, uma profissão majoritariamente branca e masculina, com pouquíssimas e raras exceções. A questão posta não se trata de um desenho ou esquadrinhamento de qualidades per si, mas de imagens que se articulam na construção de "matrizes de dominação", ou seja, imagens que tendem a naturalizar, situar e converter em lógicos lugares socialmente ocupados por mulheres negras e não-negras. Mais do que descrever os lugares que as mulheres negras ocupam, Patrícia Hill Collins (2019), situa-se na compreensão de como as estruturas se articulam para lhes colocar em lugares sociais determinados, ou seja, em como são percebidas como fora do perfil daqueles que são espertos, talentosos, competentes. Mais do que concepções erradas, equívocos, as imagens de controle se referem a como determinadas ideias são aplicadas a mulheres negras e permitem certo tratamento, imagens que constroem a realidade e produzem efeitos de poder.

Tais ideias vão desde a disponibilidade sexual, agressividade, destino ao cuidado maternal ou alheio e afins. Essas imagens tendem a construir mulheres rebaixadas, que se sentem 
inferiores as demais e acreditam não terem capacidades e aptidões além das imagens em questão. Essas imagens não se referem apenas aos negros, mas situam os sujeitos e sua humanidade e os não sujeitos e sua não humanidade. Eis todo esforço que reside na possibilidade de como mulheres negras podem se comunicar na construção a partir desse prisma, em conhecimentos e experiências divididas pelo jugo do racismo antinegro, do protagonismo frente a constante desumanização.

Para os desavisados, não é incomum receber como críticas ávidas desse tipo de visão, mostrando avanços em termos de direitos e garantias formais frente a formas de racismo e exploração. Para além das formalidades e conquistas mínimas de cidadania, o que se vive é a constante e incessante retirada de humanidade e dignidade de pessoas negras, pois antes de mais nada elas são não seres, são não humanas, não são pertencentes a tal domínio. Eis o brutal convívio com a violência gratuita e estrutural. Como situa Vargas:

Ou seja, negros vivenciam violência não por causa do que fazem, mas por causa de quem são, ou melhor, de quem não são. A violência gratuita equivale a um estado de terror que é independente de leis, direitos e cidadania. A violência gratuita é terror porque é imprevisível na sua previsibilidade, ou previsível na sua imprevisibilidade. Da perspectiva de uma pessoa negra, não se trata de perguntar se ela será brutalizada a esmo, mas quando (VARGAS, 2017, p. 93).

Eis o quadro de dor e morte que explica 80 tiros por suposto engano, crianças executadas, trabalhadores sumindo ao ir ou voltar do trabalho, mulheres estupradas e jovens linchados em praças e ruas de cidades de grande e médio porte. A morte negra não causa escândalo, causa rápidas lágrimas que se dissipam no calor de novos acontecimentos.

Nesse sentido, cabe um último e profícuo debate com Lélia Gonzalez, autora responsável por seguir caminhos que pensam a possibilidade de outro mundo, sem ceder a reformismos gratuitos. Se a condição negra é estar no lixo, é não ter qualidades, o que nos resta? O lixo vai falar, e numa boa (GONZALEZ, 2018, p. 193). Eis uma série de imagens que constroem os entendimentos mais comuns no Brasil, conforme a autora:

A primeira coisa que a gente percebe, nesse papo de racismo é que todo mundo acha que é natural. Que negro tem mais é que viver na miséria. Por que? Ora, porque ele tem umas qualidades que não estão com nada: irresponsabilidade, incapacidade intelectual, criancice, etc. e tal. Daí, é natural que seja perseguido pela polícia, pois não gosta de trabalho, sabe? Se não trabalha, é malandro e se é malandro é ladrão. Logo, tem que ser preso, naturalmente. Menor negro só pode ser pivete ou trombadinha, pois filho de peixe, peixinho é. Mulher negra, naturalmente é cozinheira, faxineira, servente, trocadora de ônibus ou prostituta (GONZALEZ, 2018, p. 193).

Essas imagens degradantes também se atualizam em outro plano, o da mulata, objeto sexual de exportação, passista que faz homens de todo Brasil e mundo perderem a cabeça no período do carnaval; por sua vez, há também a figura da mucama, aquela que carrega sua família e a dos outros nas costas, o burro de carga dos brancos, figura do cotidiano doméstico. A figura da negra prestadora de serviços pode ser atualizada e pensada a partir de tantos outros exemplos, da atendente de caixa, garçonete, zeladora e tantas outras. Não se trata de profissões e serviços em si, mas de como imagens naturalizadas sobre as mulheres negras constroem compreensões, relações de poder e tratamentos, ou seja, constroem um mundo, expectativas sobre ele e autopercepções atomizantes. Lélia Gonzalez aponta que: 
A negra anônima, habitante da periferia, nas baixadas da vida, quem sofre mais tragicamente os efeitos da terrível culpabilidade branca. Exatamente porque é ela que sobrevive na base da prestação de serviços, segurando a barra familiar praticamente sozinha. Isto porque seu homem, seus irmãos e seus filhos são objeto de perseguição policial sistemática (esquadrões da morte, "mãos brancas", estão aí matando negros à vontade; observe-se que são negros jovens, com menos de trinta anos. Por outro lado, que se veja quem é a maioria da população carcerária deste país (GONZALEZ, 2018, p. 199).

O exemplo exposto pela autora nos faz pensar tanto em singularidades da mulher negra, quanto a equação geral que incorre sobre os corpos negros. Há com recorrência corpos femininos sendo hiperexplorados, sexualizados, vendidos, estuprados, descartados, porém, há uma economia de guerra contra os corpos negros como um todo, ferindo "seus homens, irmãos $e$ filhos", uma economia que dilacera a partir da epiderme, da constatação que "ser negro é não ser humano". Aqui se mostra necessário pensar o que significa ser negra/o: estar em uma escala de exploração e violência que nos coloca em posição de inferioridade e sujeição, tanto relação a mulheres brancas, quanto a homens brancos. Grada Kilomba (2019), brilhantemente aponta sobre como um médico branco, ao atender uma menina negra, sem qualquer reserva propôs que ela "cozinhasse as refeições diárias, da família, limpasse a casa e eventualmente lavasse suas roupas. Não é muito. Alguns shorts, talvez uma camiseta e, claro, nossas roupas íntimas". (KILOMBA, 2019, p. 93), enquanto ele e sua família desfrutariam de suas férias. A questão aqui, é como uma paciente, uma criança não é vista enquanto tal, é transformada subitamente em serviçal, empregada doméstica. Assim, uma relação profissional típica entre médico-paciente é transmutada em uma relação senhor branco e mucama. Como outrem pode ser desumanizado tão rápida e naturalmente? Kilomba sugere e se mudássemos o gênero e raça de nossos personagens?

O que se segue é uma intrigante mudança de posições entre homens (branco e negro), mulheres (branca e negra) revezam-se e infortunadamente os corpos negros não ocupam posições de poder capazes de lhe sugerir a possibilidade de interpelar outrem na condição de servente e serviçal. Conforme a autora:

Esse encontro revela como "raça" e gênero são inseparáveis. "Raça” não pode ser separada do gênero nem o gênero pode ser separado da "raça". A experiência envolve ambos porque construções racistas baseiam-se em papeis de gênero e vice-versa, e o gênero tem um impacto na construção de "raça" e na experiência do racismo (KILOMBA, 2019, p. 94).

Nesse sentido, compondo o último bloco de diálogos gostaria de sugerir que a condição da mulher negra não está desatrelada de um pertencimento anterior. Ela é antes de ser mulher, negra, sendo negra, não é mulher, pois ser negro, como já se mostrou anteriormente, é não ter os atributos da humanidade disponíveis, é ser um não-ser, estar em uma zona destinada a violência gratuita e a morte prematura. Assim, antes de se poder ser mulher, inscrever seu corpo sob tal signo, esta se inscreve por um pertencimento anterior, ou um não-pertencimento, estar numa zona de corpos caídos, dilacerados, ser a menor entre os já pequenos, ter um estatuto menor entre os já apequenados, conforme situa Grada Kilomba:

O mito da mulher negra disponível, o homem negro infantilizado, a mulher mulçumana oprimida, o homem muçulmano agressivo, bem como o mito da mulher branca emancipada ou do homem

PRACS: Revista Eletrônica de Humanidades do Curso de Ciências Sociais da UNIFAP 
branco liberal são exemplos de como as construções de gênero e de "raça" interagem (KILOMBA, 2019, p. 94).

Aqui mantenho as especificidades expostas por Lélia Gonzalez ao tratar da condição da mulher negra, ao mesmo tempo em que atrelo tais características a apontamentos já expostos por ela ao pensar em racismo e sexismo: se é mulher negra ou se é negra mulher. Ao mesmo tempo, vejo uma consonância entre Lélia Gonzalez e Grada Kilomba ao pensar que gênero e raça interagem, tem efeitos mútuos sobre si e tem resultados sobre os corpos das mulheres negras de formas específicas, ao mesmo tempo que não desatrelados dos corpos negros em geral, dada a condição fundante de não-humanidade.

Assim, a possibilidade de diálogo entre as autoras parece residir no seguinte aspecto: se a condição feminina negra tem atributos especiais, estes não estão desatrelados da condição negra em geral, a não humanidade como um marcador que impõe ditames, estes por sua vez são intensificados, explorados e hiperdimensionados em uma economia da guerra contra corpos negros e aguilhoados por esquemas de dominação de gênero.

Por sua vez, a possibilidade de construção de conhecimentos a partir do prisma das mulheres negras pode revelar tanto aspectos dessa sociabilidade, quanto esquemas de resistência, construção de laços e estratégias destas em aliança, produzindo conhecimentos que explorem dimensões pouco atentas até então, que percebam construções potentes, submersas e/ou silenciadas, ou seja, pode-se situar as experiências das mulheres negras visíveis tanto na teoria quanto na história.

Tal assertiva teórica se mostra rica por: possibilitar diferentes experiências de desumanização sob o jugo do racismo antinegro, possibilitar diálogos frutíferos que podem avançar em possibilidades de construção de conhecimentos que possibilitem a relação entre mulheres negras e comunidades negras, numa produção de autoras negras e com um público negro. Por fim, pode-se complexificar e expor de forma mais contundente a relação entre mulheres negras e suas estratégias, suas leituras de mundo e a potência posta em movimento.

\section{REFERÊNCIAS}

CHAKRABARTY, Dipesh. A pós-colonialidade e o artifício da história: quem fala em nome dos passados “indianos”? Tradução Erahsto Felício, revisão Gissele Raline Moura, junho de 2009.

COLLINS, Patricia Hill. Aprendendo com a outsider within: a significação sociológica do pensamento feminista negro. Revista Sociedade e Estado, v. 31, n. 1, 99-127, jan.-abril 2016. Pensamento feminista negro: conhecimento, consciência e a política do empoderamento. São Paulo: Boitempo, 2019

FANON, Frantz. Pele negra, máscaras brancas. SciELO-EDUFBA, 2008.

GILROY, Paul. Senhores, senhoras, escravos e a antinomia da modernidade. In: O atlântico negro: modernidade e dupla consciência. Tradução de Cid Knipel Moreira. São Paulo: Editora 34, Rio de Janeiro: Universidade Cândido Mendes, Centro de estudos afro-asiáticos, 2012.

GONZALEZ, Lélia. Racismo e sexismo na cultura brasileira. In: Primavera das rosas negras: Lélia Gonzalez em primeira pessoa. Diáspora Africana: Editora Filhos da África, 2018. KILOMBA, Grada. Memórias da plantação: episódios de racismo cotidiano. Rio de Janeiro: Cobogó, 2019. 
MBEMBE, Achille. Crítica da razão negra. Lisboa: Antígona, 2014.

MEMMI, Albert. El Racismo: deficiones. Cuaderno de trabajo AFRODESC/ EURESCL No 8, Estudiar el racismo. Textos y herramientas, México, 2010.

VARGAS, João Costa. Por uma mudança de paradigma: antinegritude e antagonismo estrutural. Revista de Ciências Sociais. Fortaleza, v.48, n. 2, p.83-105, jul./dez., 2017. 